\title{
DANIELLA KEIDAR
}

The University of Haifa

\section{EMOTIONAL INTELLIGENCE AND EDUCATION}

\begin{abstract}
Keidar Daniella, Emotional Intelligence and Education [Inteligencja emocjonalna a edukacja]. Studia Edukacyjne nr 37, 2015, Poznań 2015, pp. 327-348. Adam Mickiewicz University Press. ISBN 978-83-232-0000-0. ISSN 1233-6688. DOI: 10.14746/se.2015.37.19
\end{abstract}

In recent years, the study of emotions has broadened its scope and established its standing as a new scientific discipline. Humanity has become increasing conscious of the seminal role played by the emotional components in both intrapersonal and interpersonal behavior. Research into the brain, behavior, education and medicine have been presenting, with increasing frequency, new findings and evidence proving that people with a higher I.Q. are not necessarily happier, more sociable, more communicative, more moral, more ethical, or more successful. The integration of the rational with the emotional is what guides the individual towards a behavioral result. A deeply rooted and inherent correlation exists between emotional intelligence (EI) and positive social results (PSR): adaptive abilities, the capacity for healthy social behaviors, caring, altruism, empathy as well as the tendency to bond and establish quality social relationships. By using EI skills and techniques, an educator (and the educational system at large) will be better able to achieve his educational objectives with the students not only as individuals but also as a group. The educator and the educational process are responsible for building and developing the infrastructure of EI that constitutes a major and essential part of life quality from childhood to adulthood. Emotional intelligence in the teaching sphere is highly instrumental in mutual relations between educator and students. Understanding and application of emotional intelligence in the forms of self-consciousness, control of feelings, relationship systems and enlightened communication, pave the way to concord and harmony between mind, emotion and behaviour. This coordination equips the educator with the wherewithal to teach and react consciously and emotionally and ensures his effective and educative entente with his students. Their mutual understanding creates the best possible conditions for the teaching process and for scholastic success. Our social intelligence emphasizes sensitivity to others and enables us direct our actions towards the creation of enlightened and progressive interpersonal communication.

Key words: Emotional Intelligence (EI), Cognitive ability, Emotions, Educator, Self Effective Life (SEL)

\section{Introduction}

In recent years, the study of emotions has broadened its scope and established its standing as a new scientific discipline. Humanity has become in- 
creasing conscious of the seminal role played by the emotional components in both intrapersonal and interpersonal behavior. ${ }^{1}$ At the beginning of the twentieth century, when most efforts to define intelligence concentrated on the cognitive aspects such as memory and problem solving, a number of researchers began to identify its non-cognitive aspects and related to these ideas in their work. In 1920, Edward Lee Thorndike introduced the term "social intelligence" 2 which he described as the skill of understanding and managing other people. In 1940, David Wexler related to the influence of noncognitive elements on behavior and noted that the attempt to design a model of human intelligence would not be complete without a comprehensive description of those elements. Similarly, in 1983, Howard Gardner while introducing the "theory of multiple intelligences,"3 (which claims that it is impossible to explain human behavior on the basis of a single intelligence and therefore it is necessary to dismantle the concept into a wide spectrum of learning abilities) incorporated intra and interpersonal components into his model of intelligences. Throughout the historical development of the concept, the common denominator among those concerned with the subject was the belief that conventional definitions of intelligence were lacking in the ability to explain the results of our behavior in a complete and satisfactory manner. The coining of the term "emotional intelligence"4 (in 1990 by G. Mayer and P. Salovey) and its further expansion (D. Goleman, 1995) ${ }^{5}$ placed the discipline on the public agenda thereby turning its principles into common knowledge.

Research into the brain, behavior, education and medicine have been presenting, with increasing frequency, new findings and evidence proving that people with a higher I.Q. are not necessarily happier, more sociable, more communicative, more moral, more ethical or more successful. It is becoming increasing clear that cognitive intelligence is not, in and of itself, sufficient and that in order to lead a more effective, holistic, abundant and ethical life in each of its various circles and cycles, one needs to develop and apply an additional dimension of knowledge - the emotional dimension, a dimension of life that enriches the rational one by providing information. The integration of the rational with the emotional is what guides the individual towards a behavioral result. ${ }^{6} \mathrm{~A}$ deeply rooted and inherent correla-

1 Y. Naumovsky, The Feeling is Always with Us, Israel 2006.

2 G. Orme, Emotional Intelligence, Israel 2001.

${ }^{3}$ Ibidem.

4 Ibidem.

${ }^{5}$ D. Goleman, Social Intelligence, the New Science of Human Relationships, Israel 2007.

${ }^{6} \mathrm{~K}$. Bagnoli, Morality and the Economics, Oxford 2011. 
tion exists between emotional intelligence (E.I. - Emotional Intelligence) and positive social results: adaptive abilities, the capacity for healthy social behaviors, caring, altruism, empathy as well as the tendency to bond and establish quality social relationships. ${ }^{7}$

The internal skills defined by the science of emotional intelligence - the abilities to manage, direct, guide, monitor, create, nurture and support - result in the development of an emotional repertoire on both the intrapersonal and interpersonal level. The connection between the brain and emotions is what produces a multi-dimensional human experience in the individual. In addition, this connection constitutes an immanent aspect of ethical conduct that is born out of the awareness of a "me" and a "myself" in my relations with others. Each time an individual examines what is appropriate behavior, it is also necessary to clarify the preferences of the others involved in the situation and to consider how the "me" would feel in their place. ${ }^{8}$

Emotion is what motivates human beings. It is no coincidence that the word "emotion" integrates the Latin "Muvere," to move. Underlying each thought, decision and action there exists the emotion that was imprinted somewhere in the past, developed in the present moment or that, alternatively, gazes into the future. ${ }^{9}$ Referring to Kant's dictum, "I think, therefore I am" (cogito ergo sum), Antonio Damasio ${ }^{10}$ suggests an amendment, "I feel, therefore I think, therefore I am." Indeed, the emotions are not only included in the thought processes, they are, in fact, an integral part of them.

The components located within the "container" of emotional intelligence include: empathy, decision making, the ability to convey and decipher messages (verbal and non verbal), conflict solving skills, self awareness in coping with a variety of emotions in real time, the ability to analyze emotional functioning by identifying the emotion involved, defining and expressing it as well as understanding the actions and behaviors that stem from it, expertise in processing the emotion by applying meta-cognition and a capacity for ethical and moral conduct and behavior.

Emotional intelligence is directed and proceeds along two complementary paths. The intrapersonal track includes self-awareness of cognitive and emotional processes and the connection between the two. The mode of thinking and the way of interpreting events "create" the reality that an indi-

${ }^{7}$ M. Zeidner, G. Matthews, R.D. Roberts, What We Know about Emotional Intelligence - How it Affects Learning, Work, Relationships and our Mental Health, Israel 2012; T. Clodie, Emotional Intelligence, Theory and Implementation, Israel 2005.

8 Y. Benziman, Until You are in His Place - Ethics, Impartiality, and Personal Relations, Israel 2005.

9 B. Parkinson, A.M. Colman, Emotion and Motivation, Israel 2000.

10 A. Damasio, Looking for Spinoza, Israel 2005. 
vidual experiences at any given moment. Altering thoughts and emotions enables a change in this perception of existing reality. The interpersonal track of social intelligence consists of an individual's conduct of personal and social relations in an optimal fashion including expressions of empathy, mutuality, cooperation, compassion, attentive listening, ethical conduct, flexibility, adaptability to situations in flux and the nurturing of positive emotions.

Note: "People will forget what you said, people will forget what you did, but people will never forget how you made them feel." 11

\section{The Essence of Emotional Intelligence}

EI or Emotional Quality (EQ) represents a conscious and logical link between thought and emotion leading to behavior that fosters positive relationships and optimal interactions between the self and the surrounding environment. By recruiting emotions and integrating them into the rational thought process we can create a harmony of these elements, thereby, responding out of choice and intention rather than in an impulsive, automatic manner. The application of these skills allows individuals to create, monitor, regulate, manage and direct their own responses and the responses of others towards more desirable and holistic ends in personal, interpersonal and professional encounters.

The highest distinction to be achieved by the application of emotional intelligence is to become a person who acts out of choice, a person who chooses his responses, regulates his emotions, initiates his actions and, as a result, creates and constructs meaning. Human beings tend to react spontaneously to events and situations in an automatic, primary, survival driven manner (F.F.F. - Freeze, Fight or Flight) and such reactions are likely to produce similar responses from others. Creating alternative emotional and logical response systems based on conscious choice and intention are likely to bring different and more desirable behaviors and outcomes that will improve both mental and physiological reactions to existent situations leading to a further fine-tuning of the thought process.

For example, a person that receives a flawed service often tends to become angry and impatient. This anger leads to the secretion of high amounts of adrenaline and sugar, a heightened pulse rate, profuse sweating, a weak-

11 Associated with Maya Angelou, an American author, poet and philosopher. 
ened immune system and damage to the entire physiological system. ${ }^{12}$ Situations of this kind have an additional cumulative effect and cause long term damage. Instead of this mode of reaction, it is possible to choose to produce within ourselves an entirely different emotion in response to the aforementioned flawed service. We cannot change the reality of the poor service but we can chose to create within ourselves a completely different feeling. We can change our reaction and attitude to the service by altering the prism of thinking and bypassing the automatic survival mechanism. Instead of referring to the service provider as vulgar we can, for example, decode his behavior as a sign of distress, as such that stems from a lack of proper training or frustration and not personal. We can also relate in a similar manner to other unpleasant or uncomfortable situations.

Altering how we relate to situations by changing our thought patterns initiates a highly desirable chain reaction. The physical response changes and the body's physiological systems calm down, the flow of oxygen becomes more efficient and balanced, the nervous system relaxes and becomes less constricted, muscles loosen and the immune system functions more efficiently - all of which reflect a healthier physiological state. Relaxation and balancing of the body's physiological systems enable the brain to initiate more positive processing (when the body and its systems are under stress, the brain tends, as a survival measure, to first process threatening negative data) leading to thinking abilities of a qualitatively improved caliber capable of desirable behavioral responses based on choice rather than instinct and impulsivity. Emotionally intelligent people know how to combine logic and emotions. This integration is manifested in the capacity to remain alert and aware of the nature of the emotions occurring within oneself and within others and the ability to express and regulate them through the conscious thought processes that nurture and improve the quality of life in both intrapersonal and interpersonal relationships. People who are aware of their emotions can monitor them, connect with them and create internal control mechanisms. As a result, these individuals are able to take moral and ethical aspects of their behavior into consideration before responding to life's challenges.

Note: One can choose how to react, direct and manage one's feelings. Reality is the interpretation that one gives to a given situation. Man is the architect of his life.

12 S.M. Talbott, The Cortisol Connection, Focus, Israel 2005. 
Being that the concept of emotional intelligence has been informed by a wide spectrum of practical and theoretical approaches, a multiplicity of definitions and measurement standards have been suggested. It is possible to identify three significant models that offer a framework for the definition and measurement of emotional intelligence:

\section{Emotional Intelligence as a Cognitive Ability (EI Ability)}

Emotional intelligence integrates the domains of intelligence and emotions by relating to emotions as a source of vital information which assists us in understanding and navigating the social environment. It consists of four distinctive abilities. The first is emotional perceptiveness, the ability to identify and decipher emotions in facial expressions, pictures, sounds and objects. Accurate appraisal of our emotions enables us to utilize emotional data in decision making and comprehending the emotions of others. The capacity to understand and experience the emotions of others (empathy) constitutes a social skill essential to maintaining positive interpersonal relations. The second is the utilization of emotions, the ability to harness our emotions for the benefit of various cognitive processes such as thought, contemplation, and problem solving and choosing between options. The third ability, the understanding of emotions and emotional knowledge, includes the capacity to understand "emotional language" and the complex connections between different emotions, to accurately distinguish between emotions (for instance between happy and enthusiastic) and to identify and describe their development over time. Emotional information relates to an understanding of the underlying causes and the consequences of emotions and moods, their development and the changes they undergo over time. The fourth ability is actually the ability to combine all the above mentioned three abilities and know how to act and which action to take in a manner that will balance coherently between one's cognition, emotions and behavior.

Cognitive understanding of the components of emotion enables a person to process emotional developments in real time, to identify and utilize that data efficiently. For example: when an emotionally aware individual reacts angrily to a certain situation, it is possible for him to almost immediately employ cognitive processing to identify the emotion, understand its source and define its nature. Anger might contain feelings of frustration, impotence, fear, sadness or disappointment. Cognitive understanding of the components of emotions enables better regulation and re-routing in the direction of a specifically desired response. Emotional monitoring aims to achieve emo- 
tional balance in ourselves and in others, control of our emotions in accordance with a given situation and the ability to harness emotions (even negative ones) to obtain a desired result. The management of another's emotions refers to the ability to influence, persuade and change another's position; in other words, a tool for social influence by means of creating enthusiasm, motivation and movement in a specific direction.

The essence of emotional intelligence as a cognitive ability lies in the possibility of delaying the spontaneous, automatic, survival driven response in unpleasant situations in order to allow the planning of a more appropriate response aimed at fostering more reciprocal and effective communication. The ability of the individual to respond consciously by employing the advantages of a broader vision, more complex thought and more intentional behavior allow a person to take moral principles and behavior into consideration. Making well considered judgments moderates the human tendency to egoistic outbursts and permits a wider spectrum of empathetic behavior including attentive listening, empathy and openness.

\section{Emotional Intelligence as a Character Trait (EI Trait)}

The character trait of emotional intelligence (also referred to as emotional self efficacy), is defined as a tendency towards a constellation of behaviors and self-perceptions regarding the ability of an individual to identify, process and utilize emotional knowledge. The classification of emotional intelligence as a character trait is grounded in the assumption of its behavioral potential. A genetic element has been attributed to traits such as optimism and pessimism. Emotional self efficacy can be nurtured, intensified or diminished. Its development is greatly dependent on the individual's primary and the extended environment including early childhood education, K-12 schools and the academic world. For example, an individual with critical and judgmental tendencies will be likely to display behaviors that are counterproductive to positive interpersonal relationships. In such a case, educational intervention aimed at promoting self-awareness and the acquisition of attitudes that encourage openness, equality and respect for the dignity and unique qualities of others can be transformative.

\section{An Integrated Model for Emotional Intelligence}

Emotional Intelligence is comprised of cognitive abilities and personality traits. This model posits the integration between the two as necessary for the 
enhancement of individual and societal welfare. It is the ensemble of emotional and social characteristics that determine the degree of efficacy in our ability to understand ourselves and others, to express ourselves, to communicate with others and to cope with the demands of daily life. Emotional intelligence develops over time and can be improved by relevant training. Individuals with a high emotional quotient are better equipped to succeed in meeting the challenges, demands and pressures presented by the ever changing environment. A person's success and welfare are dependent on cognitive, emotional and behavioral flexibility and the ability to adapt to changing conditions.

Three of the fundamental and essential components of emotional intelligence are interwoven: self-awareness, the regulation of emotions and the ability to conduct enlightened, reciprocal communication and relationships. Awareness of these elements and the ability to activate them form an important basis for all interpersonal dynamics and interactions and the foundation of ethical and moral behavior:

\section{Self-Awareness}

Self awareness is defined as an individual's ability to understand the emotional dynamics, the thoughts and attitudes underlying daily interaction on both the intrapersonal and interpersonal planes. Emotions and reactions to them generally flow unconsciously and often prevent effective internal and external processes. The transition from a lack of consciousness to a consciousness of these processes focuses the individual, allowing for the formulation of effective and productive behavior patterns. ${ }^{13}$ Self-awareness consists of :

- The ability to identify physiological changes in diverse and dynamic situations.

- The ability to make connections between physical signals and emotions.

- The ability to recognize negative thinking.

- The ability to identify a variety of emotions and to self-evaluate.

- The ability to distinguish between emotions and actions.

- The ability to develop realistic expectations about oneself and one's relationships.

${ }^{13}$ A. Damasio, Looking for Spinoza. 
- Recognition of the relationship between thoughts, emotions and response. The ability to distinguish between each of the above elements and to understand them both as separate and connected.

- The ability to control and direct thoughts, emotions and behavior for personal benefit.

Note: It is important that an educator, who is a role model to his students, will remember that referring to others starts with one's self-awareness. There are two ways of spreading one's light: to be the candle or the mirror that reflects it.

\section{Regulating Emotions}

Emotions arise as an automatic reaction to given circumstances. The responses and behavior of individuals are often determined by their emotions. Control, regulation and monitoring of emotions allow a person to consciously choose reactions and create desirable situations through an intelligent combination of rational and emotional processes.

Regulating emotions includes:

- The ability to calm down in situations involving stress, anger and anxiety.

- The ability to convert negative and destructive thoughts into more positive ones.

- The ability to convert "catastrophic" images into rational ones.

- Identifying the way we relate to and interpret different events.

- Identifying which senses are activated at a given moment.

- Recognizing the interpretive process and the ways in which different kinds of information are processed. The ability to differentiate between thoughts, emotions, behavior and personal prejudices.

- The ability to identify mood shifts and regulate moods in accordance with our intentions through our thought processes.

- The ability to identify when our behavior is defensive or aggressive and the ability to manipulate such situations for more beneficial results.

- An awareness of the effect of our moods and behavior on others.

- The ability to change behavior within the dynamics of interpersonal relationships.

- The ability to free oneself from old patterns of behavior and habits that are not beneficial and to develop new emotional, cognitive and behavioral patterns in order to create a better quality of life and improved relationships. 
Note: Flexibility, adaptability, capability and one's self management are basic tools for creating one's self-esteem and personal evaluation.

The above mentioned list presents the principles of emotional regulation that allow an individual to choose the manner and nature of his responses. For example, in a conflict between two people, one of them raises his voice and screams. The common automatic, survival driven reaction is to yell back in return because we think that we do not deserve such behavior or because we feel that the other person is being rude or intentionally hurtful. When we activate our "delaying mechanism" we are able to pause before we respond, to think about how to improve the situation, to put our ego aside and to try to understand that the other person's conduct that might stem from distress. We can utilize the special ability afforded to human beings, the ability to chose our response rather than react solely from a survival driven position. Daniel Goleman ${ }^{14}$ describes these transitions as the movement from the base or primitive mode of response to an enlightened one that is accomplished by utilizing the cognitive brain to monitor the emotional brain. In order to possess a moral sensibility, we must understand the moods and mind states of others and be sensitive to them. Acknowledging the "other" means recognizing that others have their own beliefs, thoughts, dreams and intentions. The cornerstone of morality is the capacity to understand the other on both the cognitive and emotional planes. ${ }^{15}$

\section{Relationships and Enlightened Communication}

Relationships are generally characterized by a dynamic and spontaneous flow during which we tend to place greater emphasis on ourselves and less on others. Transferring the focus of attention to others by emphasizing the four central tenets of loving, learning, understanding and attentive listening will steer relationships towards a higher level of interpersonal dynamics.

Emotional intelligence is manifested in relationships with others by:

- The ability to convey verbal and non-verbal messages (thoughts, feeling, experiences and behaviors) in a clear, efficient, trust inducing way.

- The ability to recognize and decipher messages (emotions) of others through active, dynamic, empathic listening.

14 D. Goleman, Social Intelligence.

${ }^{15}$ R. Winston, Human Instinct, Israel 2005. 
- The development of assertive behavior-expressing thoughts, desires and emotions without denying the thoughts, desires and emotions of others.

- Developing the skills necessary to offer and receive feedback in a way that will lead to progress, change, openness and the establishment of effective and productive channels of communications in a diversity of relationships.

The aforementioned distinctive qualities describe conduct that creates and enables enlightened and effective interpersonal relations and are, in practice, immanent characteristics of ethical and moral behavior. The mechanism that monitors when and in what manner an individual reacts towards another combines thought and emotion and activates the internal moral compass that regulates our behavior towards others.

Note: The cornerstone of interpersonal dynamics lies in an individual's selfawareness of his own internal dialogues.

\section{The Role, Importance and Influence of the Educator in the Educational Process}

The educator's role is to teach and educate his students. Effective education and teaching does not merely depend on the educator's professional and academic knowledge and skills (which are of course important elements in education) but also depends on how well the educator is able to transfer his knowledge to the students. Education is a tri-polar process where educator, students and the learned material are interlocked. Using the educator's EI skills effectively in transferring knowledge might be one of the best solutions and means to cause the students grasp the learned material immanently and remember it effectively for a long period of time. ${ }^{16}$ It should be remembered that though students might attend a same class or course they are not necessarily attentive to the same methods of learning and are not motivated to learn and absorb the learned material in the same manner. ${ }^{17}$ Therefore, recognizing and observing differences in teaching and learning styles at one's students, as well as being able to connect with them as individuals as well as a group, is a crucial and important element for producing a beneficial outcome. By using EI skills and techniques an educator (and the

${ }^{16}$ E. Jensen, Teaching with the Brain, Israel 2003.

17 Ibidem. 
educational system at large) will be better able to achieve his educational objectives with the students not only as individuals but also as a group. ${ }^{18}$

The educator and the educational process are responsible for building and developing the infrastructure of EI that constitutes a major and essential part of one's life quality from childhood to adulthood. One of the most important targets and aims of education is to develop personal skills and qualifications within the students for the creation of self-effective life (SEL). The creation of SEL is possible through the correct bond between cognition and emotion. In recent years awareness to the influence of emotions over thinking thus over self and social functioning has been grown. One's self ability to manage and navigate under certain circumstances one's emotions and at the same time use them for improving one's way of thinking is very important for SEL. In a longitudinal study made in the U.S.A. (a Federal program for fostering children at preschool - Izard - 2002) it was found that emotional knowledge education strongly contributed to one's mental abilities and academic achievements. In addition, developing EI allows for better selfregulation and social communication. Ergo, it is important and essential that an educator will equip his students with tools and means that will allow them to create SEL.

SEL is manifested in a person's being pro active, one who chooses his reactions concerning himself, the situations and the surroundings out of self awareness which is being expressed by the correct bond between cognition and feelings. Reactive person responses automatically out of his "ancient survival brain" and not out of choice. Reactive responses usually hurt SEL. The role of the educational process is to direct, teach, navigate and encourage pro activeness. The base and foundation for that is the development of self awareness and awareness to others. Intense self-awareness contains two main elements which are capable of influencing other people's emotions, thoughts and conduct and cause changes in their communicativeness at the speaker's will.

One of these two elements is the educator's consciousness of and sensitivity to the emotional, physiological, mental and behavioural tendencies of the ego, recognition of their strength and acquisition of the ability to guide and direct them into channels of effective communication controlled by him.

It should be recorded that there are educators who, without realizing what they do, develop friendliness and preference for some of their students while at the same time they feel indifference to and even antipathy for others. A person's mode of expression, tone of voice and manner of address will unintentionally convey his true feeling to one student or another. His ap-

18 C. Tal, Emotional Intelligence: Theory \& Implication, Israel 2005. 
proach to an individual student, benign or aggressive, patient or impatient, radiating satisfaction or dissatisfaction, will invite an identical reaction by his student. Upon his realization of this fact, a revolution in those of his habitual approaches to students which have probably prejudiced his reputation will open new pathways to reasonable, mutual relations between him and them. ${ }^{19}$

The other element is the educator's consciousness of, and sensitivity to the emotional, physiological, mental and behavioural tendencies of his fellow men enabling him to turn his attributes into instruments of effective communication.

It should be emphasized here that the educator should detect crises and disquiet among his students. As soon as he has diagnosed emotional stress in a student, as demonstrated by such indications as signs of impatience, agitation, inattention, fiddling with things unconnected with the lesson, he should devote a personal address to the student with some such remark as, "I seem to detect dissatisfaction", "I shall be pleased if you are ready to share your feelings on the matter with me".

It is important to have within the dynamics of the educational process the following central elements that constitute the educational infrastructure: Empathy, containment, listening, patience, tolerance and respect. These ingredients are the milestones and compass in each and every educational message. ${ }^{20}$

Note: SEL is reflected in one's ability to be pro active, to choose one's thoughts, emotions and reactions concerning one's inner world as well as one's reactions to others.

To heighten his personal awareness, both internally and in his contact with others, the educator can exploit the availability of the following accessible and applicable means:

1) Use of verbal expressions of feeling. It is important to employ such language as "it seems to me...", "I feel that...", "it appears to me that...", "from your words it would appear that...", "I see that...". Since people operate their senses of vision and hearing together with their feelings in general when they digest the data given out to them, the educator's use of words connoting feeling gives him a common denominator with his stu-

19 B. Parkinson, A.M. Colman, Emotions and Motivation; M. Zeidner, G. Matthews, R.D. Roberts, What We Know About Emotional Intelligence.

${ }^{20}$ M. Gilboa, Egoism of Hymanity - A voyage, Israel 1990; N. Aloni, On Becoming Human Philosophy of Education: An Anthology, Israel 2005. 
dents and prepares the arena in which communication will be unhampered. Although everyone has his own favourite sense which is more dominant than the others, employment of a variety of the senses specifies, sharpens and is more akin to the process of message transmission. Sensory declarations through sight, hearing, smell, taste and touch are at the source of all our worldly knowledge. By using the refinement of personal messages provided by their passage through the sensory channels (though taking into account coulters) we can enable our neighbours to experience our own feelings and reach a better understanding of our meanings.

Another advantage of the use of verbal expressions relating to feeling derives from the fact that it makes the educator seem to have abandoned his pretensions to the role of Mr. Know-all because as such he may excite antagonism and argument with anyone of his students who may be convinced that he is himself the one and only Mr. Know-all. Instead, he appears to be collating and adding his interpretation of the available data as prompted by his own personal feeling and offering it to his students as the product of his own meditation. In this way he minimizes the possibility of friction with members of his class. Emotional intelligence, by providing room for other people's interpretations of the didactic material, opens the door to the elimination of misunderstandings.

2) Alliance of feeling with knowledge. When the educator imparts his knowledge, he should ally it to declarations of his feelings. In this way he discloses his satisfaction or dissatisfaction with the doctrines and theories he is retailing. In so doing he clearly signals his inner reactions to the lesson he gives and his readiness to hear his students' comments. Emotional exposures contribute to the clarity of the picture.

When students adopt a behavioural pattern which is not exactly what the educator expects, he can interpolate his feeling into the expression of his opinion of their behaviour, with such words as, "it grieves me to witness such a reaction to the situation because...". Queen Victoria of England's reaction would be "we are not amused!". Upon occasions, to advertise his satisfaction, he might say "it makes me happy to see that you have been given a clear picture of...". In another situation it might be, "I doubt if we can manage to take it all in but I'll be glad if we can master the first half".

3) Recognition of the link between thought, feeling and reaction. The combined operations of mind, emotion and instinctive reaction never cease during a person's lifetime. Sometimes it is the mind that directs the emotion toward a specific type of reaction or behaviour pattern. At other times certain feelings prey on the mind translating themselves into types of behav- 
iour and reactions. The educator must sense and become conscious of these processes and know how to pilot his students out of troubled waters.

An educator who does not like or does not think much of one of his students may possibly betray his disapproval or aversion in his attitude to the selfsame student in the classroom by revealing disinterest when the student speaks or by the way he looks at the student. When his demonstrations of dislike become a habit, the student will react accordingly. Upon his realization of this process the educator can correct his behaviour and rid himself of the habit. The educator can think things over and say to himself, "I thoroughly realize that the student gets my dander up, but upon deeper consideration I can think of no objective reason for my dislike. I must therefore take deeper interest in his words." Consciousness of his own prejudices will lead to a change in his attitude to the student and a new pattern of relationship will be draughted between them.

Note: It is essential to recognize the operations of mind, emotion and behaviour, so that the potency of one or all of them may be modified according to specification. Awareness of one's own self puts a person in control of his behaviour.

\section{Emotional Intelligence and the Transmission of Useful Feedback by the Educator}

Feedback is intended to assist a person to achieve those very objectives which he strives to attain. It is difficult to make feedback stick because the person at whom it is aimed feels hurt. Quite often this results in the latter's withdrawal into himself, his assumption of a defensive attitude and a decision to stand his ground. It is destructive feedback which ensures such reactions as demoralization, loss of motivation and harm to a person's selfrespect. Positive feedback encourages the desire to achieve, study, cooperate and obtain results. ${ }^{21}$ Planning the right strategy of correction should be uppermost in the mind of the educator. It should be helpful, inciting initiative and not prejudicial to the student's ego. The tactical moves which the educator may make are as follows:

1. Time and place. The right time and place should be carefully selected. The showdown should not take place in the presence of an audience. The task must be performed privately, in the form of a tête à tête, in congenial surroundings and where educator and student can make themselves com-

${ }^{21}$ R. Bailey, NLP Counseling, Oxfordshire 1997. 
fortable. If, for example, where they sit there is no barrier, such as a desk, between them, conditions becomes favourable for friendly communication.

2. Emphasis on the positive features. The educator should start with a word of praise for the positive features of his pupil's viewpoint. By no means should he speak scathingly of the student as a student, of his potential, of his mental equipment or of his scholastic attainments. While he is thrusting his feedback, it will serve his purpose to lay occasional emphasis on such sugar to the pill as, "I realize the importance of your voicing your views", or "your participation and readiness to air your views are highly commendable but...". One might also say, "much as I appreciate the thoughts you have devoted to the subject and the words in which you have chosen to express them, I would have expected you to choose more apposite language."

3. Choice of method. In a review of his choice of methods for dealing with the problem the educator must ascertain the weak points in his student's character and take them into consideration in order to avoid ruffling him up. His attack must be launched against the student's mistake which calls for correction rather than against the person who made the mistake.

4. Homework. feedback requires careful preparation beforehand. One must examine every word of it with a magnifying glass and be certain that the changes which the feedback evokes will be the right ones. The main question which the critic must ask himself is, "What shall we both gain by it? How will my role of critic affect me? How will the victim of my feedback be advantaged? By hook or by crook I must contrive a happy end to the affair with the heightened estimation of, and improved communication between both parties."

5. Let sleeping dogs lie. The educator should refrain from listing or keeping a log of students' past indiscretions, whether they be interruptions, misbehaviour or impolite actions. This does not conduce to improved relations. It is preferable for the educator to shut out the past and pin his hopes on future prospects. Let us suppose that a certain student is in the habit of interrupting when I am in the middle of a definition of my ideas. I must not say, "you always cut me off in the middle, as you did yesterday and last week". You might just as well be saying, "I accuse!", thereby inviting undesirable reaction with the offender setting up his line of defence. More correctly, I might say, "Look! I am always ready to give you a hearing, but I would prefer completing my words before supplying you with my opinion of your view on my message in its entirety."

6. Observation of one's reaction. The educator must be closely observant of all the student's reactions, inclusive of the latter's facial expressions 
and his total body language. If, during the educator's talk with the student he feels that his critical language is causing discomfort or tension, he should change tack and adopt more soothing language. Sometimes it might even be advisable to say something like, "if this is an inopportune moment for our talk, we can meet again."

7. Suggesting alternatives. If the educator provides himself with alternatives to the opinion which has roused his feedback and offers them to the student, he will be saving the student's face by revealing that he is prepared to honour the student's ability to make decisions and formulate points of view when he chooses what he considers the best alternative to his original idea which was considered unacceptable.

8. Expression of personal feelings. When the educator chooses the words in which he cloaks his feedback, he should include expressions of his personal feelings. He might say, "I am sure you can do better!" or "I feel that we shall find a change of approach more profitable!" or "I shall be glad to learn how you feel about it."

9. The right of response. It is vital to ensure that the person who is criticised is given the right to express himself and to be affected by the emotional messages which are transferred together with the spoken facts. In conclusion, the critic should paraphrase the words of the student with the addition of terms expressing feeling, such as, "you give me to understand that our discussion has made you most unhappy!"

10. Cui bono? Repetition and emphasis. It is most important to conclude with a repetition of the benefit to be derived from the changed situation and to end on a pleasant note. The person who has had to listen to the educator's censure should be thanked for his cooperation and the hope should be voiced that his changes of opinion and behaviour will make him a wiser and better man.

Note: The objective of feedback is to create positive and productive change. It should benefit the critic as well as the person who is criticised. This can be achieved only if the student is given motivation to create the change. The change can be effected only by the activation of cooperation and constructive communication.

Emotional intelligence in the teaching sphere is highly instrumental in mutual relations between educator and students. Understanding and application of emotional intelligence, in the forms of self-consciousness, control of feelings, relationship systems and enlightened communication, pave the way to concord and harmony between mind, emotion and behaviour. This 
coordination equips the educator with the wherewithal to teach and react consciously and emotionally and ensures his effective and educative entente with his students. Their mutual understanding creates the best possible conditions for the teaching process and for scholastic success. Our social intelligence emphasizes sensitivity to others and enables us direct our actions towards the creation of enlightened and progressive interpersonal communication.

In order to develop skills and abilities in EI it is important to teach the following subjects in every educational process starting from early childhood through adolescence and during one's adulthood. The following subjects constitute the infrastructure for the building of a personal as well as inter personal quality of life:

1. Human Communication - Introducing the notion theoretically, scientifically and practically in the every day life in general and in teaching in particular.

2. E.I. Systems - Knowing the various systems in Emotional Intelligence and their use in general and in teaching in particular.

3. Communication Channels - The use and influence of communication channels in the teaching process - the use of various ways of expressions and the broadcasting of facts, thoughts, feelings and needs.

4. NVC - Non Verbal Communication - The power and influence of the NVC in relationship systems in general and in teaching in particular.

5. Developing Listening Skills - Identifying listening barriers at the other person - means and ways to absorb useful and effective information. Developing listening skills and their absorptions at the students.

6. NLP - Neuro Linguistic Programming - The spoken language, its influence on the neuro-psychological system and its use in teaching and teaching.

7. E.I. as a Tool - Emotional Intelligence as a tool for developing motivation at the students.

8. E.I. as a Tool - Emotional Intelligence as a tool for reducing personal and interpersonal violence at students.

9. E.I. and the Brain - The essence and role of the Emotional Intelligence - A connection between the brain, thoughts, feelings and behavior.

10. E.I. as Tool - Emotional Intelligence and interpersonal communication as a didactic tool in teaching.

11. Advanced Professional Communication - Practical processes for creating change; opinion and viewpoint crystallization; creating convincing processes in the daily dynamics. 
12. E.I. and the Process of Decision Making - Identifying and using emotional and cognitive characteristics in the every day decision making.

13. Positive Thinking and Humor - A practical tool in teaching.

14. Brain, Emotion and Behavior - Making the correct connection between these components in coping with the every day stresses and pressures.

15. Intrapersonal and Interpersonal Norms and Ethics - Their importance and influence in teaching.

\section{How it is done?}

We should ask ourselves how a country's huge and complex educational system would manage to make a so sharp and extremely needed and essential turn towards the development of EI at its educational system. After assimilating the pedagogical implications of EI, it is recommended to start the process by training teachers the notions, concepts and ideas of EI. Teachers' training institutions at colleges and universities will educate teachers' trainees to be familiar and oriented in the multidisciplinary world from which EI drives - neurobiology, neuropsychology, and physiology. After being familiar with the basic structure of the human brain and its pedagogical implications, the teachers trainees will study areas of knowledge that are essential for establishing and developing EI - philosophy, psychology, cognition sciences etc. Simultaneously the trainees will experience self-awareness workshops and EI cultivating teaching methods.

The second step would be the training of Parents - organizing workshops and training meetings for parents concerning EI, especially stressing and emphasizing the need to nourish and nurture communication channels between parents and their children. The third step would be to provide each educational institute (or if there are budgetary constraints for two or three as a bunch) with an expert who will be responsible to develop EI in them. Such an expert will guide the children, the kindergarten teachers, the pupils, school teachers, school managers and parents in EI and will systematically take care of the three elements of EI (Cognition, Emotion, and Behavior).

The fourth step would be to emphasis EI in a study program which will include "direct" engagement in the various scientific elements of EI as well as directions concerning social interactions, and an "indirect" practice stressing the learned material in EI eyes e.g. if teaching bible or history, how biblical or historical figures would have used EI. The same would apply to other learning subjects and courses. The fifth step would include teaching pat- 
terns and will emphasis the experiential dimension of study that will induce emotional involvement, will develop imagination, foster curiosity and encourage creativity. The sixth step would be the developing of evaluating system that will take into account every child's personal progress and his ability to identify his feelings, positively express them and conduct them in accordance with the circumstances. It should also be emphasized that school's physical buildings and its organizational climate should be adapted to the goal - developing EI. The comfort and beauty of the building and proper organizational climate will broadcast and induce ease and respect to the students and teachers alike. Positive communication and mutual listening will instill a climate of cooperation.

Educators are fortunate enough to have received the privilege, opportunity and possibility to immensely shape future generations and society's image. Society's quality of life, even its mere existence, depends on proper educational targets and of their intelligent and rational use. Proper educational target, if not the most important of them all, is to develop by means of the country's educational system youngsters' EI.

\section{Conclusion}

Developing and cultivating EI in education constitutes the infrastructure for optimal behavior. The (correct) connection between cognition and emotion is essential and crucial for the creation of one's ability of self competence, self esteem and the ability to adapt to the very dynamic life.

One of the most basic ways of instilling elements of emotional intelligence in the individual begins with the attempt to teach them to "feel" from the earliest possible age. A person understands himself, others, his environment and his motivations better when he is connected to his emotions. In addition to questions such as "What do you think?" or "What's your opinion?" we should also ask, "How do you feel?" and encourage the individual to continue to pose questions of his own in the same spirit. ${ }^{22}$ These kinds of questions create a correlation between the rational world and the emotional one. Emotional functioning, by influencing rational functioning, can bring beneficial effects but, more importantly, it can facilitate internal growth and well-being. Daniel Goleman ${ }^{23}$ claims that our society is emotionally bankrupt. According to the studies that he cites, there has been continued emo-

\footnotetext{
${ }^{22} \mathrm{E}$. Jensen, Teaching with the Brain in Mind.

${ }^{23}$ D. Goleman, Social Intelligence.
} 
tional deterioration among American children aged 7-17 in comparison to findings from the middle of the 1970's and the end of the 1980's. This deterioration is reflected in increased rates of anxiety, depression, loneliness, alienation, social problems, attention deficit disorders, violent behavior, addictions, lack of discipline, inability to cope with failure, and a general sense of malaise and feeling of a deep emotional lack that is reflected in a difficulty to find meaning in life. A higher grade in English or math will not necessarily fill inner emptiness, provide moral direction, or strengthen the sense of competence in a student. The development of emotional intelligence in the toddler, the young child, the adolescent, the student and the adult is the most effective and practical path to filling an emotional vacuum and to imbuing the life of the individual and society as a whole with a sense of significance and meaning that bear moral and ethical weight.

It is clear that if we desire to promote emotional intelligence as a practical tool able to improve interpersonal and social communication as well as assist in establishing and maintaining ethical norms and codes, we cannot be satisfied with just promoting its principles and skills among young children and waiting until that generation matures and takes their place among the leaders or hold other influential positions in society. It must be promoted at every opportunity and in every framework possible that will contribute to significant improvement in the existing situation.

Our social quality of life depends on its individuals' quality of life. The essence, role and responsibility of the educator and the educational system are to build the infrastructure of the individual's thus society's quality of life from a very young age. Such a way of education will enable an enlightened and immanent human communication that will bring in turn the foundation of the globalization of quality of life to the human species.

\section{BIBLIOGRAPHY}

Aloni N., On Becoming Human Philosophy of Education: An Anthology, Hakibutz Hameuchad \& Mofet Institute, Israel 2005.

Bagnoli K., Morality and the Economics, Oxford University Press, Oxford 2011.

Bailey R., NLP Counseling, Roy Bailey Publishing, Winslow Press, Oxfordshire 1997.

Benziman Y., Until You are in His Place - Ethics, Impartiality, and Personal Relations, Magnes, Israel 2005.

Clodie T., Emotional Intelligence, Theory and Implementation, Ach \& Mofet Publishing, Israel 2005.

Damasio A., Looking for Spinoza, Opus, Israel 2005.

Gilboa M., Egoism of Hymanity - A voyage, Dvir, Israel 1990 Goleman D., Social Intelligence, the New Science of Human Relationships, Aliyat Gag, Israel 2007. 
Jensen E., Teaching with the Brain, The Branco Weiss Institute for the Development of Thinking, Israel 2003.

Naumovsky Y., The Feeling is Always with Us, Yosef Publishin, Israel 2006.

Orme G., Emotional Intelligence, Ach Publishing House, Israel 2001.

Parkinson B., Colman A.M., Emotion and Motivation, Ach Publishing Hause, Israel 2000.

Tal C., Emotional Intelligence: Theory \& Implication, Ach \& Mofet Publishing, Israel 2005.

Talbott S.M., The Cortisol Connection, Focus, Israel 2005.

Winston R., Human Instinct, Tel-Aviv University, Israel 2005.

Zeidner M., Matthews G., Roberts R.D., What We Know about Emotional Intelligence - How it Affects Learning, Work, Relationships and our Mental Health, Emek Israel Publishing, Israel 2012. 